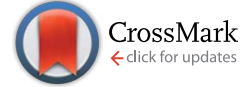

Cite this: Chem. Sci., 2016, 7, 3676

Received 25th November 2015 Accepted 30th January 2016

DOI: $10.1039 / \mathrm{c} 5 \mathrm{sc0} 04521 \mathrm{e}$

www.rsc.org/chemicalscience

\section{Efficient metal-free photochemical borylation of aryl halides under batch and continuous-flow conditions $\uparrow$}

\author{
Kai Chen, Shuai Zhang, Pei He and Pengfei Li* \\ A rapid, chemoselective and metal-free $\mathrm{C}-\mathrm{B}$ bond-forming reaction of aryl iodides and bromides in \\ aqueous solution at low temperatures was discovered. This reaction is amenable to batch and \\ continuous-flow conditions and shows exceptional functional group tolerance and broad substrate \\ scope regarding both the aryl halide and the borylating reagent. Initial mechanistic experiments indicated \\ a photolytically generated aryl radical as the key intermediate.
}

\section{Introduction}

Arylboronic acids and esters have found broad applications in chemical, medicinal and materials sciences. In synthetic organic chemistry, in particular, they are versatile synthons for the formation of carbon-carbon or carbon-heteroatom bonds. ${ }^{1}$ Conventional methods for generating arylboron compounds involve reactions of arylmetallic intermediates with trialkyl borates, followed by transesterification or hydrolysis. These reactions suffer some major drawbacks such as limited functional group tolerance as well as the necessity of rigorous anhydrous conditions (Scheme 1a). ${ }^{2}$ In recent decades, transition metal-catalyzed borylation reactions using palladium, nickel, copper and zinc have emerged as highly useful methods for the conversion of $\mathrm{C}-\mathrm{X}$ bonds to $\mathrm{C}-\mathrm{B}$ bonds (Scheme $1 \mathrm{~b}$ ). ${ }^{3}$

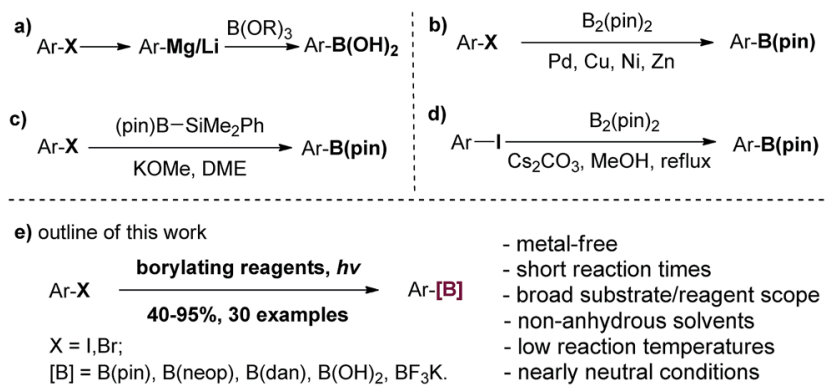

Scheme 1 Summary of borylation reactions of aryl halides and outline of this work.

Center for Organic Chemistry, Frontier Institute of Science and Technology (FIST), Xi'an Jiaotong University, 99 Yanxiang Road, Xi'an, Shaanxi, 710054, China. E-mail: lipengfei@mail.xjtu.edu.cn

$\dagger$ Electronic supplementary information (ESI) available: Experimental procedures and characterization of new compounds are provided. See DOI: $10.1039 / \mathrm{c} 5 \mathrm{sc} 04521 \mathrm{e}$
More recently, direct $\mathrm{C}-\mathrm{H}$ borylation methods based on transition-metal catalysts have also been developed. ${ }^{4}$ In order to reduce the costs and the amount of heavy metal residue in the final products, several transition-metal-free methods for C-B bond formation have been developed. Ito and coworkers discovered an alkali alkoxide-mediated borylation of aryl halides with a silylborane as the unique borylating reagent (Scheme 1c). ${ }^{5}$ Zhang and coworkers reported that aryl iodides could be borylated with 4.0 equivalents of bis(pinacolato) diboron in refluxing methanol using 2.0 equivalents of $\mathrm{Ce}_{2} \mathrm{CO}_{3}$ as the promoter. The reaction time ranged from several hours to days and the yields were generally moderate (Scheme $1 \mathrm{~d}$ ). ${ }^{6}$ Fernándes and Muñiz transformed diaryliodonium acetates to arylboronates under mild conditions. ${ }^{7}$ Using aryl amines as the starting material, Wang developed a mild and efficient Sandmeyer-type borylation process. ${ }^{8 a-c}$ Borylation of aryl diazonium salts $^{8 d-f}$ and aryl triazenes ${ }^{8 g}$ has also been reported. In addition, innovative methods for direct $\mathrm{C}-\mathrm{H}$ borylation under transition metal-free conditions have been reported, ${ }^{9}$ although the substrates were limited to either electron rich arenes or heterocycles, and air and moisture sensitive reagents were needed. Consequently, a practical, metal-free method that is rapid and effective, works under mild conditions with various readily available borylating reagents, shows high functional group tolerance and avoids strong acids, bases and hazardous reagents is still highly desirable. Herein, we wish to report our discovery and development of a new borylation reaction of aryl halides using light as a clean reagent (Scheme 1e). ${ }^{10}$

\section{Results and discussion}

Initially, a solution of 4-iodoanisole (1a) and bis(pinacolato)diboron (2) in acetonitrile was placed in a quartz test tube and irradiated with a $300 \mathrm{~W}$ high pressure mercury lamp (maximum at $365 \mathrm{~nm}$ ) for 4 hours. Encouragingly, the desired aryl-B(pin) product 3a was formed in $29 \%$ yield based on ${ }^{1} \mathrm{H}$ NMR analysis 
of the crude product (Table 1, entry 1). Other polar solvents such as trifluoroethanol and methanol did not improve the reaction (entries 2 and 3). Adding water and acetone as co-solvents was beneficial in both cases and increased the yield to $46 \%$ (entries 4 and 5). Screening of various organic and inorganic additives revealed that an organic base, $N, N, N^{\prime}, N^{\prime}$-tetramethyldiaminomethane (TMDAM), could further improve the yield to 58\% (entry 9). By comparison, other bases led to inferior results (entries 6-8). Interestingly, a greater amount of TMDAM led to a significantly lower yield (entry 10). Using two equivalents of $\mathrm{B}_{2}(\text { pin })_{2}$ could improve the yield to $72 \%$ (entry 11). Further optimization by changing the reaction concentration of 1a resulted in a higher yield ( $c=0.1 \mathrm{M}, 81 \%$ yield) (entry $12 v s .11$ and 13).

During the study, we observed gradual decomposition of $\mathrm{B}_{2}(\mathrm{pin})_{2}$. We felt that continuous-flow photolytic conditions might help in reducing the amount of $\mathrm{B}_{2}$ (pin $)_{2}$ by competitively accelerating the desired reaction. In comparison with a typical batch photoreactor, microchannel photochemical reactors have significant benefits for reaction efficiency, yield, reproducibility, material throughput and scale-up. ${ }^{\mathbf{1 1 - 1 3}}$ Based on the method developed by Booker-Milburn ${ }^{\mathbf{1 1 a}}$ and our own experience in flow chemistry, ${ }^{14}$ we designed and assembled a continuous-flow photochemical reactor. Thus, transparent fluorinated ethylene propylene (FEP) tubing (reaction volume $780 \mu \mathrm{L}$ ) was coiled

Table 1 Reaction optimization under batch and continuous-flow conditions

\begin{tabular}{lllll}
\hline & & & \\
\hline
\end{tabular}

\section{Batch conditions ${ }^{a}$}

$\begin{array}{lllll}1 & 1.0 & \mathrm{MeCN} & \text { None } & 29 \\ 2 & 1.0 & \mathrm{TFE} & \text { None } & 26 \\ 3 & 1.0 & \mathrm{MeOH} & \text { None } & 15 \\ 4 & 1.0 & \mathrm{MeCN} / \mathrm{H}_{2} \mathrm{O} & \text { None } & 42 \\ 5 & 1.0 & \mathrm{MeCN} / \mathrm{H}_{2} \mathrm{O} / \text { acetone } & \text { None } & 46 \\ 6 & 1.0 & \mathrm{MeCN} / \mathrm{H}_{2} \mathrm{O} / \text { acetone } & \mathrm{Cs}_{2} \mathrm{CO}_{3}(100) & 16 \\ 7 & 1.0 & \mathrm{MeCN} / \mathrm{H}_{2} \mathrm{O} / \text { acetone } & \mathrm{KO}^{t} \mathrm{Bu}(100) & 12 \\ 8 & 1.0 & \mathrm{MeCN} / \mathrm{H}_{2} \mathrm{O} / \text { acetone } & \text { TMEDA (50) } & 52 \\ 9 & 1.0 & \mathrm{MeCN} / \mathrm{H}_{2} \mathrm{O} / \text { acetone } & \text { TMDAM (50) } & 58 \\ 10 & 1.0 & \mathrm{MeCN} / \mathrm{H}_{2} \mathrm{O} / \text { acetone } & \text { TMDAM (100) } & 39 \\ 11 & 2.0 & \mathrm{MeCN} / \mathrm{H}_{2} \mathrm{O} / \text { acetone } & \text { TMDAM (50) } & 72 \\ \mathbf{1 2}^{d} & \mathbf{2 . 0} & \mathbf{M e C N} / \mathrm{H}_{2} \mathrm{O} / \text { acetone } & \text { TMDAM (50) } & \mathbf{8 1} \\ 13^{e} & 2.0 & \mathrm{MeCN} / \mathrm{H}_{2} \mathrm{O} / \text { acetone } & \text { TMDAM (50) } & 55\end{array}$

\section{Flow conditions ${ }^{b}$}

$\begin{array}{lllll}14 & 2.0 & \text { MeCN } / \mathrm{H}_{2} \mathrm{O} / \text { acetone } & \text { TMDAM (50) } & 87 \\ 15 & 1.5 & \text { MeCN/ } / \mathbf{H}_{2} \text { O/acetone } & \text { TMDAM (50) } & \mathbf{8 8}\end{array}$

${ }^{a}$ Batch conditions: $1 \mathrm{a}(0.1-0.2 \mathrm{mmol}, c=0.05 \mathrm{M} / 0.1 \mathrm{M}), 2(0.1-0.4$ mmol), RT, 4 h. ${ }^{b}$ Flow conditions: $1 \mathrm{a}(c=0.1 \mathrm{M}),-5{ }^{\circ} \mathrm{C}$, residence time 15 min. ${ }^{c}$ Determined by ${ }^{1} \mathrm{H}$ NMR with $1,3,5-$ trimethoxybenzene as an internal standard. ${ }^{d} c=0.1 \mathrm{M} .{ }^{e} c=0.2$ M; TMEDA: N,N,N,N-tetramethylethylenediamine; TMDAM: $N, N, N^{\prime}, N^{\prime}$-tetramethyldiaminomethane. around a jacketed quartz immersion well in which the mercury lamp was situated. The reaction temperature was regulated by a cooling liquid circulating pump (see ESI $\dagger$ ). A stock solution containing all reactants and reagents was introduced into the tubing using a syringe pump. To our delight, running the reaction under the same conditions as entry 12 but in continuous-flow mode gave $3 \mathbf{a}$ in excellent yield (87\%, entry 14) with a residence time of only 15 minutes. Indeed, the amount of $\mathrm{B}_{2}(\mathrm{pin})_{2}$ could be reduced to 1.5 equivalents without affecting the reaction efficiency ( $88 \%$ yield, entry 15 ).

With the optimized conditions in hand, we examined the substrate scope of the current borylation reaction under batch and/or continuous-flow conditions, as summarized in Table 2. Iodoarenes with various electron-donating, -neutral and -withdrawing groups at the para-, meta-, or ortho-positions, including hydroxyl, amino, amide, ester, acid, ketone, cyano, fluorine, boronate and trifluoromethyl groups, were all efficiently converted to the corresponding aryl pinacol boronates in good to

Table 2 Substrate scope of the photolytic borylation ${ }^{a}$
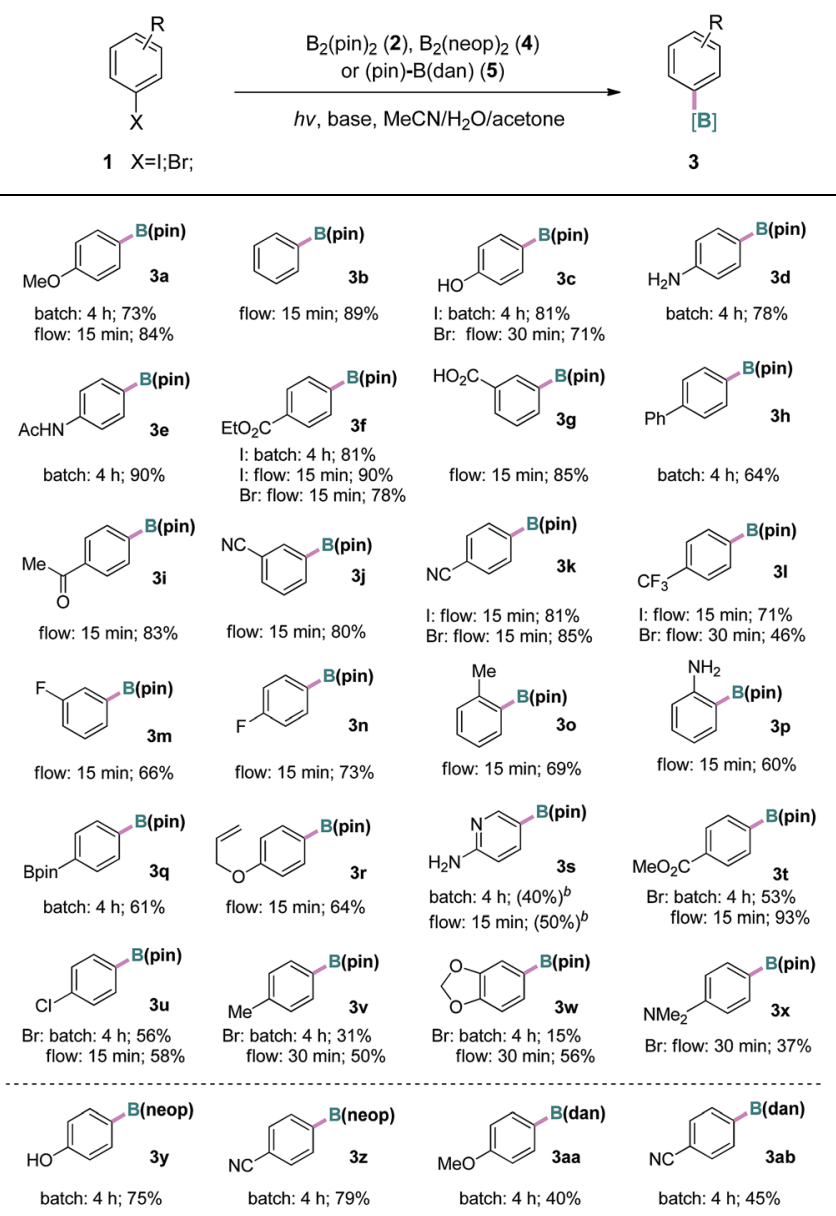

${ }^{a}$ Batch conditions: 1a $(0.2 \mathrm{mmol}, c=0.1 \mathrm{M}), 2$ (0.4 mmol, 2.0 eq.), TMDAM (0.5 eq.), RT, 4 h; flow conditions: $1 \mathrm{a}(c=0.1 \mathrm{M}), 2$ (1.5 eq.), TMDAM (0.5 eq.), $-5{ }^{\circ} \mathrm{C}$, residence time $15-30 \mathrm{~min} .{ }^{b}$ Determined by ${ }^{1} \mathrm{H}$ NMR with 1,3,5-trimethoxybenzene as an internal standard; TMDAM: $N, N, N^{\prime}, N^{\prime}$-tetramethyldiaminomethane. 
excellent yields (3a-3r). Groups potentially reactive under UV light such as aryl ketone (for $\mathbf{3 i}$ ) and biaryl (for $\mathbf{3 h}$ ) were compatible. A substrate containing an allyl ether group was also viable (3r), which is interesting considering that the reaction might involve a reactive carbon-based radical and the double bond could be attacked. In addition, the borylation of 2-amino5 -iodopyridine was possible, and a moderate yield of the corresponding boronate $3 \mathrm{~s}$ was observed by ${ }^{1} \mathrm{H}$ NMR spectroscopic analysis. Attempts to purify $3 \mathbf{s}$ were unsuccessful due to its decomposition on silica gel. Furthermore, when aryl bromides were subjected to the same reaction conditions, the desired products were produced in comparable or slightly lower yields than the iodides $(\mathbf{3 c}, \mathbf{3} \mathbf{f}, \mathbf{3 k}, \mathbf{3} \mathbf{l}$ and $\mathbf{3 t}-\mathbf{3 x})$. Finally, different borylating reagents were utilized under otherwise identical conditions. Reactions using bis(neopentanediolato)diboron $\mathrm{B}_{2}$ (neop) $)_{2}$ successfully afforded the desired products in good yields (3y and 3z). Interestingly, when an unsymmetrical diboron (pin)B-B(dan) was employed, selective introduction of the $\mathrm{B}$ (dan) moiety was realized (3aa and $\mathbf{3 a b}$ ) and no aryl pinacol boronate was observed. ${ }^{15}$ To demonstrate the stability and usefulness of this reaction in larger scale preparation, the borylation reactions of iodobenzene and 4-iodophenol were carried out at gram scale $(10.0 \mathrm{mmol})$ employing a commercial automated flow chemistry system (reactor volume $7.8 \mathrm{~mL}$, see ESI $\dagger$ ). Without any further optimization, the reactions produced the desired arylboronate products in excellent isolated yields ( $\mathbf{3 b}$ $90 \%$ and $3 \mathrm{c} 93 \%$ ) and the productivity corresponded to $\sim 3$ mmol h${ }^{-1}$.

Encouraged by the above results, we further investigated the possibility of using a more atom economical borylating reagent, bis-boronic acid (BBA, 6). Largely because its polar protic properties may not be amenable to most known borylation methods, this reagent has only recently been successfully used in palladium or nickel-catalyzed Miyaura borylation by Molander and coworkers. ${ }^{16}$ In the present borylation, pleasingly, we were able to convert 4-iodoanisole 1a to the corresponding boronic acid 7a under continuous-flow conditions in quantitative yield based on ${ }^{1} \mathrm{H}$ NMR analysis (residence time 10 minutes). The key variation from the previous conditions was using aqueous methanol $\left(\mathrm{MeOH}: \mathrm{H}_{2} \mathrm{O}=4: 1 \mathrm{v} / \mathrm{v}\right)$ as the solvent. Due to the inconvenience of isolating the pure arylboronic acid, aqueous $\mathrm{KHF}_{2}$ was added and the resulting potassium aryltrifluoroborate 8a was obtained in 93\% yield. Other aryl and heteroaryl iodides and a bromide were also transformed to the boronates in good to excellent yields in this manner (Table 3).

To gain insight into the reaction mechanism, and particularly to probe the role of additives and light, we conducted a series of control experiments (Table 4). When the batch reaction of 1 with $\mathrm{B}_{2}(\mathrm{pin})_{2}$ was run under the standard conditions, deiodination product 9 was formed in $7 \%$ yield in addition to the borylation product $\mathbf{3 f}$ (entry 1 ). In the absence of both TMDAM and light (entry 2), no conversion was observed. However, the reaction with 0.5 equivalents of TMDAM in the dark led to a small amount of $\mathbf{3 f}$ (entry 3); higher reaction temperatures and prolonged reaction time had little influence on the outcome. A hydrogen atom donor, $\mathrm{Bu}_{3} \mathrm{SnH}$, increased the
Table 3 Continuous-flow photolytic borylation with $\mathrm{B}_{2}(\mathrm{OH})_{4}$

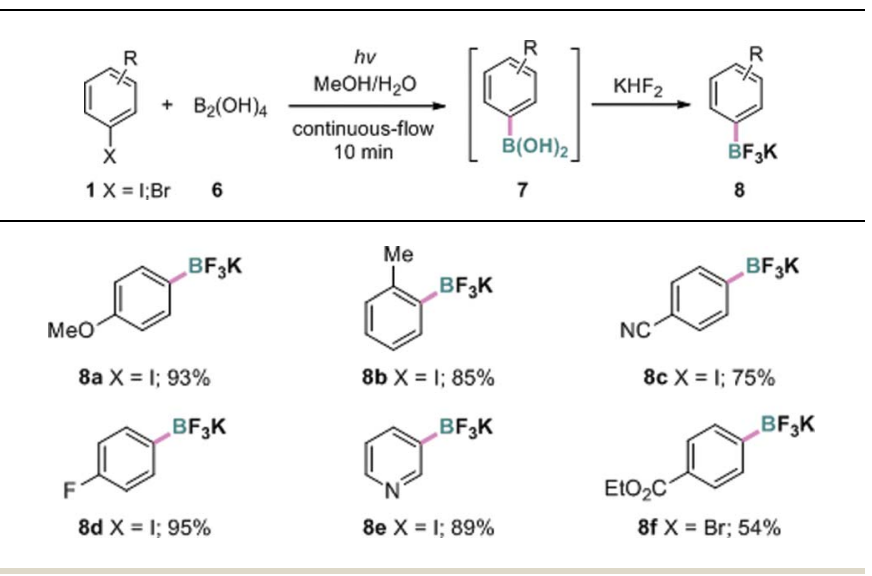

conversion but led to $\mathbf{9}$ as the major product (entry 4). Furthermore, the reaction with $\mathrm{Bu}_{3} \mathrm{SnH}$ under UV irradiation afforded 9 in high yield (entry 5). Similarly, using 9,10-dihydroanthracene instead of $\mathrm{Bu}_{3} \mathrm{SnH}, 9$ (26\%) and concomitant anthracene (11\%) were observed (entry 6). Finally, when TEMPO was added as a radical scavenger, the conversion was low and four products including $3 \mathbf{f}(15 \%), 9$ (11\%), the aryl-TEMPO adduct 10 (14\%) and ethyl 4-hydroxybenzoate 11 (26\%) were formed (entry 7).

Based on the experimental results and related reports on photolytic reactions of aryl iodides, ${ }^{17}$ we propose two pathways both involving an aryl radical intermediate as the possible reaction mechanism (Scheme 2). The excited state 12 is generated by UV irradiation of aryl iodide 1 . In path A, 12 undergoes homolytic C-I bond cleavage to form aryl radical $\mathbf{1 3}$ and an

Table 4 Control experiments for preliminary mechanistic studies ${ }^{a}$

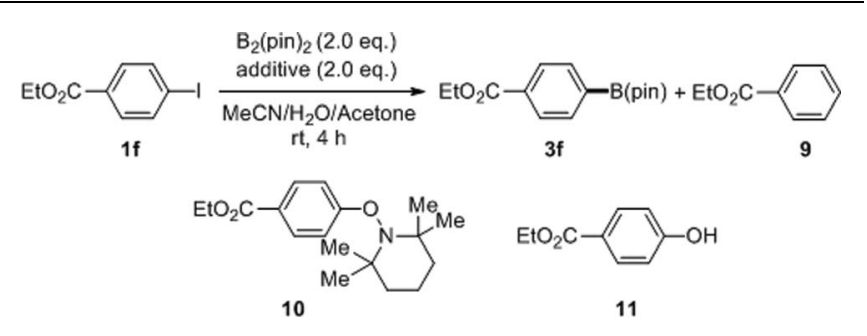

\begin{tabular}{lllllll} 
Entry & Light & TMDAM & Additive & $\begin{array}{l}\text { Conversion } \\
{[\%]}\end{array}$ & $\begin{array}{l}\text { Yield of 3f } \\
{[\%]}\end{array}$ & $\begin{array}{l}\text { Yield of } 9 \\
{[\%]}\end{array}$ \\
\hline 1 & + & + & - & 100 & 81 & 7 \\
2 & - & - & - & 0 & 0 & 0 \\
3 & - & + & - & 13 & 13 & 0 \\
4 & - & + & $\mathrm{Bu}_{3} \mathrm{SnH}$ & 46 & 17 & 26 \\
5 & + & + & $\mathrm{Bu}_{3} \mathrm{SnH}$ & 100 & 18 & 80 \\
6 & + & + & $\mathrm{DHA}$ & 68 & 42 & $26^{b}$ \\
7 & + & + & TEMPO & 69 & 15 & 11
\end{tabular}

${ }^{a}$ Reactions were run in batch and yields were determined by ${ }^{1} \mathrm{H}$ NMR spectroscopic analysis with 1,3,5-trimethoxybenzene as an internal standard. ${ }^{b} 11 \%$ of anthracene was formed. TMDAM: $N, N, N^{\prime}, N^{\prime}$ tetramethyldiaminomethane; DHA: 9,10-dihydroanthracene; TEMPO: (2,2,6,6-tetramethylpiperidin-1-yl)oxyl. 


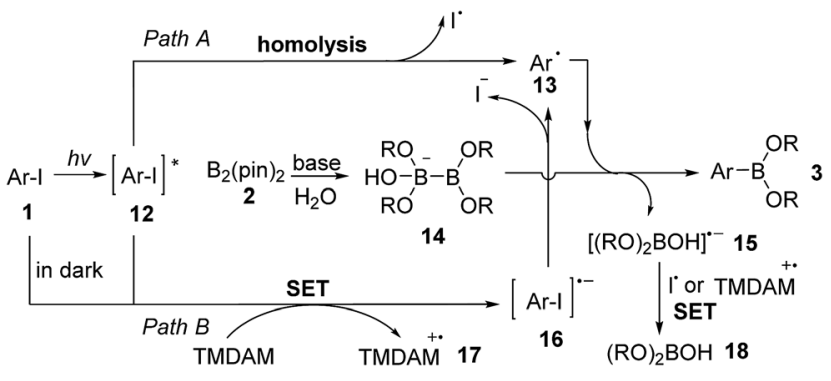

Scheme 2 Proposed reaction mechanism.

iodine atom. Under aqueous conditions, TMDAM activates a water molecule, combining with $\mathrm{B}_{2}(\mathrm{pin})_{2}$ (2) to form a sp ${ }^{3}-\mathrm{sp}^{2}$ diboron species 14. ${ }^{7,8 f, 18}$ Aryl radical 13 then reacts with 14 to produce arylboronate 3 and a boryl radical anion $15 .{ }^{19} 15$ can also be viewed as an anionic base-stabilized boryl radical. ${ }^{20}$ Alternatively, in path B, the excited state $\mathbf{1 2}$ or the starting aryl iodide $\mathbf{1}$ (when in darkness, although with low efficiency) is reduced by TMDAM via a single electron transfer (SET) process to form radical anion $\mathbf{1 6}$ and TMDAM-derived radical cation 17. 16 then undergoes C-I bond cleavage to generate aryl radical 13 and iodide anion. Finally, $\mathbf{1 5}$ is oxidized by the iodine atom from path A or TMDAM-derived radical cation $\mathbf{1 7}$ from path B to form borate $\mathbf{1 8}$ as a byproduct.

\section{Conclusions}

In summary, we have discovered a novel and efficient photolytic borylation reaction of aryl halides using diboron reagents. This metal-free reaction features very mild conditions, short reaction times, generally high yields and broad functional group tolerance. Considering the reaction conditions, borylating reagent types and possible reaction mechanism, this work represents an important complementary approach to the existing $\mathrm{C}-\mathrm{B}$ bond formation methods. Further studies on the mechanism and synthetic applications of this reaction are ongoing.

\section{Acknowledgements}

This work was financially supported by the NSFC (No. 21472146), the Department of Science and Technology of Shaanxi Province (No. 2015KJXX-02) and the Ministry of Science and Technology of the People's Republic of China (No. 2014CB548200). We thank Prof. Que (Xi'an Jiaotong University) and Dr Duncan Guthrie (Vapourtec) for their generous sharing of the batch and flow photochemistry equipment.

\section{Notes and references}

1 For reviews on arylboronic acid derivatives, see: $(a)$ N. Miyaura and A. Suzuki, Chem. Rev., 1995, 95, 2457; (b) D. G. Hall, in Boronic Acids: Preparation and Applications in Organic Synthesis, Medicine and Materials, ed. D. G. Hall, Wiley-VCH, Weinheim, 2011, pp. 1-134; (c) J. Yamaguchi, A. D. Yamaguchi and K. Itami, Angew. Chem., Int. Ed., 2012,
51, 8960; (d) L. Xu, S. Zhang and P. Li, Chem. Soc. Rev., 2015, 44, 8848.

2 (a) H. C. Brown and T. E. Cole, Organometallics, 1983, 2, 1316; (b) H. C. Brown, M. Srebnik and T. E. Cole, Organometallics, 1986, 5, 2300; (c) O. Baron and P. Knochel, Angew. Chem., Int. Ed., 2005, 44, 3133; (d) C. Pintaric, S. Olivero, Y. Gimbert, P. Y. Chavant and E. Duñach, J. Am. Chem. Soc., 2010, 132, 11825.

3 (a) T. Ishiyama, M. Murata and N. Miyaura, J. Org. Chem., 1995, 60, 7508; (b) W. Zhu and D. Ma, Org. Lett., 2006, 8, 261; (c) K. L. Billingsley, T. E. Barder and S. L. Buchwald, Angew. Chem., Int. Ed., 2007, 46, 5359; (d) C. M. So, C. P. Lau and F. Y. Kwong, Angew. Chem., Int. Ed., 2008, 47, 8059; (e) C. Kleeberg, L. Dang, Z. Lin and T. B. Marder, Angew. Chem., Int. Ed., 2009, 48, 5350; (f) D. A. Wilson, C. J. Wilson, C. Moldoveanu, A. M. Resmerita, P. Corcoran, L. M. Hoang, B. M. Rosen and V. Percec, J. Am. Chem. Soc., 2010, 132, 1800; $(g)$ Y. Nagashima, R. Takita, K. Yoshida, K. Hirano and M. Uchiyama, J. Am. Chem. Soc., 2013, 135, 18730; (h) C. Zarate, R. Manzano and R. Martin, J. Am. Chem. Soc., 2015, 137, 6754; (i) S. K. Bose and T. B. Marder, Org. Lett., 2014, 16, 4562; (j) W. K. Chow, O. Y. Yuen, P. Y. Choy, C. M. So, C. P. Lau, W. T. Wong and F. Y. Kwong, $R S C A d v$. 2013, 3, 12518; $(k)$ T. Niwa, H. Ochiai, Y. Watanabe and T. Hosoya, J. Am. Chem. Soc., 2015, 137, 14313; $(l)$ S. K. Bose, A. Deißenberger, A. Eichhorn, P. G. Steel, Z. Lin and T. B. Marder, Angew. Chem., Int. Ed., 2015, 54, 11843.

4 For selected references on catalytic $\mathrm{C}-\mathrm{H}$ borylation, see: $(a)$ I. A. I. Mkhalid, J. H. Barnard, T. B. Marder, J. M. Murphy and J. F. Hartwig, Chem. Rev., 2010, 110, 890; (b) C. N. Iverson and M. R. Smith III, J. Am. Chem. Soc., 1999, 121, 7696; (c) H. Chen, S. Schlecht, T. C. Semple and J. F. Hartwig, Science, 2000, 287, 1995; (d) T. Ishiyama, J. Takagi, K. Ishida, N. Miyaura, N. R. Anastasi and J. F. Hartwig, J. Am. Chem. Soc., 2002, 124, 390; (e) S. Kawamorita, H. Ohmiya, K. Hara, A. Fukuoka and M. Sawamura, J. Am. Chem. Soc., 2009, 131, 5058; $(f)$ H. X. Dai and J. Q. Yu, J. Am. Chem. Soc., 2012, 134, 134; $(g)$ T. J. Mazzacano and N. P. Mankad, J. Am. Chem. Soc., 2013, 135, 17258; (h) L. Xu, S. Ding and P. Li, Angew. Chem., Int. $E d$., 2014, 53, 1822; (i) J. V. Obligacion, S. P. Semproni and P. J. Chirik, J. Am. Chem. Soc., 2014, 136, 4133; (j) L.-S. Zhang, G. Chen, X. Wang, Q.-Y. Guo, X.-S. Zhang, F. Pan, K. Chen and Z.-J. Shi, Angew. Chem., Int. Ed., 2014, 53, 3899; (k) G. Wang, L. Xu and P. Li, J. Am. Chem. Soc., 2015, 137, 8058; (l) S. Shimada, A. S. Batsanov, J. A. K. Howard and T. B. Marder, Angew. Chem., Int. Ed., 2001, 40, 2168; $(m)$ H. Tajuddin, P. Harrisson, B. Bitterlich, J. C. Collings, N. Sim, A. S. Batsanov, M. S. Cheung, S. Kawamorita, A. C. Maxwell, L. Shukla, J. Morris, Z. Lin, T. B. Marder and P. G. Steel, Chem. Sci., 2012, 3, 3505.

5 (a) E. Yamamoto, K. Izumi, Y. Horita and H. Ito, J. Am. Chem. Soc., 2012, 134, 19997; (b) R. Uematsu, E. Yamamoto, S. Maeda, H. Ito and T. Taketsugu, J. Am. Chem. Soc., 2015, 137, 4090; (c) E. Yamamoto, S. Ukigai and H. Ito, Chem. Sci., 2015, 6, 2943. 
6 J. Zhang, H.-H. Wu and J. Zhang, Eur. J. Org. Chem., 2013, 6263.

7 N. Miralles, R. M. Romero, E. Fernándes and K. Muñiz, Chem. Commun., 2015, 51, 14068.

8 (a) F. Mo, Y. Jiang, D. Qiu, Y. Zhang and J. Wang, Angew. Chem., Int. Ed., 2010, 49, 1846; (b) W. Erb, A. Hellal, M. Albini, J. Rouden and J. Blanchet, Chem.-Eur. J., 2014, 20, 6608; (c) D. Qiu, L. Jin, Z. Zheng, H. Meng, F. Mo, X. Wang, Y. Zhang and J. Wang, J. Org. Chem., 2013, 78, 1923; (d) J. Yu, L. Zhang and G. Yan, Adv. Synth. Catal., 2012, 354, 2625; (e) R. D. Dewhurst, E. C. Neeve, H. Braunschweig and T. B. Marder, Chem. Commun., 2015, 51, 9594; $(f)$ S. Pietch, E. C. Neeve, D. C. Apperley, R. Bertermann, F. Mo, D. Qiu, M. S. Cheung, L. Dang, J. Wang, U. Radius, Z. Lin, C. Kleeberg and T. B. Marder, Chem.-Eur. J., 2015, 21, 7082; (g) C. Zhu and M. Yamane, Org. Lett., 2012, 14, 4560.

9 (a) A. Prokofjevs, J. W. Kamf and E. Vedejs, Angew. Chem., Int. Ed., 2011, 50, 2098; (b) L. Niu, H. Yang, R. Wang and H. Fu, Org. Lett., 2012, 14, 2618; (c) V. Bagutski, A. D. Grosso, J. A. Carrillo, I. A. Cade, M. D. Helm, J. R. Lawson, P. J. Singleton, S. A. Solomon, T. Marcelli and M. J. Ingleson, J. Am. Chem. Soc., 2013, 135, 474; (d) M. A. Légaré, M. A. Courtemanche, É. Rochette and F.-G. Fontaine, Science, 2015, 349, 513; (e) S. K. Bose and T. B. Marder, Science, 2015, 349, 473.

10 (a) Synthetic Organic Chemistry, ed. A. G. Griesbeck and J. Mattay, Marcel Dekker, New York, 2005. For selected recent examples, see: (b) S. E. Creutz, K. J. Lotito, G. C. Fu and J. C. Peters, Science, 2012, 338, 647; (c) W. Liu, L. Li and C. J. Li, Nat. Commun., 2015, 6, 6526; (d) K. G. Maskill, J. P. Knowles, L. D. Elliott, R. W. Alder and K. I. BookerMilburn, Angew. Chem., Int. Ed., 2013, 52, 1499.

11 For selected references on continuous-flow photochemical reactions, see: (a) B. D. A. Hook, W. Dohle, P. R. Hirst, M. Pickworth, M. B. Berry and K. I. Booker-Milburn, J. Org. Chem., 2005, 70, 7558; (b) Y. S. M. Vaske, M. E. Mahoney, J. P. Konopelski, D. L. Rogow and W. J. McDonald, J. Am. Chem. Soc., 2010, 132, 11379; (c) F. Lévesque and P. H. Seeberger, Angew. Chem., Int. Ed., 2012, 51, 1706; (d) D. C. Harrowven, M. Mohamed, T. P. Gonçalves, R. J. Whitby, D. Bolien and H. F. Sneddon, Angew. Chem., Int. Ed., 2012, 51, 4405; (e) R. S. Andrews, J. J. Becker and M. R. Gagne, Angew. Chem., Int. Ed., 2012, 51, 4140; $(f)$ J. W. Tucker, Y. Zhang, T. F. Jamison and C. R. J. Stephenson, Angew. Chem., Int. Ed., 2012, 51, 4144; (g) K. G. Maskill, J. P. Knowles, L. D. Elliott, R. W. Alder and K. I. B. Milburn, Angew. Chem., Int. Ed., 2013, 52, 1499; (h) Y. Zhang, M. L. Blackman, A. B. Leduc and T. F. Jamison, Angew. Chem., Int. Ed., 2013, 52, 4251; (i) X. Wang, G. D. Cuny and T. Noël, Angew. Chem., Int. Ed., 2013, 52, 7860 .
12 For early pioneering work on flow photochemistry, see: $(a)$ H. Lu, M. A. Schmidt and K. F. Jensen, Lab Chip, 2001, 1, 22; (b) K. Ueno, F. Kitagawa and N. Kitamura, Lab Chip, 2002, 2, 231.

13 For selected recent reviews on flow photochemistry, see: $(a)$ M. Oelgemöller and O. Shvydkiv, Molecules, 2011, 16, 7522; (b) J. P. Knowles, L. D. Elliott and K. I. Booker-Milburn, Beilstein J. Org. Chem., 2012, 8, 2025; (c) L. D. Elliott, J. P. Knowles, P. J. Koovits, K. G. Maskill, M. J. Ralph, G. Lejeune, L. J. Edwards, R. I. Robinson, I. R. Clemens, B. Cox, D. D. Pascoe, G. Koch, M. Eberle, M. B. Berry and K. I. Booker-Milburn, Chem.-Eur. J., 2014, 20, 15226.

14 (a) P. Li and S. L. Buchwald, Angew. Chem., Int. Ed., 2011, 50, 6396; (b) P. Li, J. S. Moore and K. F. Jensen, ChemCatChem, 2013, 5, 1729.

15 L. Xu and P. Li, Chem. Commun., 2015, 51, 5656.

16 (a) G. A. Molander, S. L. J. Trice and S. D. Dreher, J. Am. Chem. Soc., 2010, 132, 17701; (b) G. A. Molander, S. L. J. Trice, S. M. Kennedy, S. D. Dreher and M. T. Tudge, J. Am. Chem. Soc., 2012, 134, 11667; (c) G. A. Molander, L. N. Cavalcanti and C. Garcia-Garcia, J. Org. Chem., 2013, 78, 6427.

17 (a) A. G. Sage, T. A. A. Oliver, D. Murdock, M. B. Crow, G. A. D. Ritchie, J. N. Harvey and M. N. R. Ashfold, Phys. Chem. Chem. Phys., 2011, 13, 8075; (b) M. Budén, J. F. Guastavino and R. A. Rossi, Org. Lett., 2013, 15, 1174; (c) J. Kan, S. Huang, H. Zhao, J. Lin and W. Su, Sci. China: Chem., 2015, 58, 1329; (d) E. H. Discekici, N. J. Treat, S. O. Poelma, K. M. Mattson, Z. M. Hudson, Y. Luo, C. J. Hawker and J. R. Alaniz, Chem. Commun., 2015, 51, 11705.

18 (a) M. Gao, S. B. Thorpe and W. L. Santos, Org. Lett., 2009, 11, 3478; (b) A. Bonet, H. Gulyás and E. Fernández, Angew. Chem., Int. Ed., 2010, 49, 5130; (c) A. Bonet, C. PubillUlldemolins, C. Bo, H. Gulyás and E. Fernández, Angew. Chem., Int. Ed., 2011, 50, 7158; (d) H. Wu, J. M. Garcia, F. Haeffner, S. Radomkit, A. R. Zhugralin and A. H. Hoveyda, J. Am. Chem. Soc., 2015, 137, 10585; (e) S. B. Thorpe, J. A. Calderone and W. L. Santos, Org. Lett., 2012, 14, 1918 and references therein.

19 (a) P. P. Power, Chem. Rev., 2003, 103, 789; (b) H. Braunschweig, V. Dyakonov, J. O. C. Jimenez, K. Kraft, I. Krummenacher, K. Radacki, A. Sperlich and J. Wahler, Angew. Chem., Int. Ed., 2012, 51, 2977 and references therein.

20 (a) S.-H. Ueng, M. M. Brahmi, E. Derat, L. Fensterbank, E. Lacôte, M. Malacria and D. P. Curran, J. Am. Chem. Soc., 2008, 130, 10082; (b) D. Lu, C. Wu and P. Li, Chem.-Eur. J., 2014, 20, 1630; (c) P. R. Rablen and J. F. Hartwig, J. Am. Chem. Soc., 1996, 118, 4648; (d) J. A. Baban and B. P. Roberts, J. Chem. Soc., Chem. Commun., 1983, 1224; (e) D. Lu, C. Wu and P. Li, Org. Lett., 2014, 16, 1486; $(f)$ J. Lalevée, N. Blanchard, M.-A. Tehfe, A.-C. Chany and J.-P. Fouassier, Chem.-Eur. J., 2010, 16, 12920. 